OPEN ACCESS

Edited by:

José A. Melero,

Instituto de Salud Carlos III, Spain

Reviewed by:

Youichi Suzuki,

Osaka Medical College, Japan

Takayuki Hishiki,

Tokyo Metropolitan Institute of Medical

Science, Japan

*Correspondence:

Wei-Kung Wang

wangwk@hawaii.edu

Specialty section:

This article was submitted to

Virology,

a section of the journal

Frontiers in Microbiology

Received: 14 March 2017 Accepted: 06 July 2017

Published: 20 July 2017

Citation:

Tsai W-Y, Lin H-E and Wang W-K (2017) Complexity of Human Antibody

Response to Dengue Virus: Implication for Vaccine Development.

Front. Microbiol. 8:1372.

doi: 10.3389/fmicb.2017.01372

\section{Complexity of Human Antibody Response to Dengue Virus: Implication for Vaccine Development}

\author{
Wen-Yang Tsai, Hong-En Lin and Wei-Kung Wang *
}

Department of Tropical Medicine, Medical Microbiology and Pharmacology, John A. Burns School of Medicine, University of Hawaii at Manoa, Honolulu, HI, United States

The four serotypes of dengue virus (DENV) are the leading cause of arboviral diseases in humans. Decades of efforts have made remarkable progress in dengue vaccine development. Despite the first dengue vaccine (dengvaxia from Sanofi Pasteur), a live-attenuated tetravalent chimeric yellow fever-dengue vaccine, has been licensed by several countries since 2016, its overall moderate efficacy $(56.5-60.8 \%)$ in the presence of neutralizing antibodies during the Phase $2 \mathrm{~b}$ and 3 trials, lower efficacy among dengue naïve compared with dengue experienced individuals, and increased risk of hospitalization among young children during the follow-up highlight the need for a better understanding of humoral responses after natural DENV infection. Recent studies of more than 300 human monoclonal antibodies (mAbs) against DENV have led to the discovery of several novel epitopes on the envelope protein recognized by potent neutralizing mAbs. This information together with in-depth studies on polyclonal sera and B-cells following natural DENV infection has tremendous implications for better immunogen design for a safe and effective dengue vaccine. This review outlines the progress in our understanding of mouse mAbs, human mAbs, and polyclonal sera against DENV envelope and precursor membrane proteins, two surface proteins involved in vaccine development, following natural infection; analyses of these discoveries have provided valuable insight into new strategies involving molecular technology to induce more potent neutralizing antibodies and less enhancing antibodies for next-generation dengue vaccine development.

\section{Keywords: dengue virus, antibody, envelope protein, precursor membrane protein, epitopes}

\section{INTRODUCTION}

The four serotypes of dengue virus (DENV) cause the most common and important arboviral diseases in humans (Guzman and Harris, 2015). Approximately 390 million DENV infections occur annually with 20-25\% apparent infection, including dengue fever (DF), and a severe and potentially life-threatening disease, dengue hemorrhagic fever (DHF), and dengue shock syndrome (DSS) (World Health Organization, 2009; Bhatt et al., 2013; Guzman and Harris, 2015). Decades of efforts have made tremendous progress in dengue vaccine development; several candidate vaccines are currently in different phases of clinical trials (Murphy and Whitehead, 2011; Schwartz et al., 2015). Despite the Sanofi Pasteur's dengvaxia, a live-attenuated chimeric yellow fever-dengue tetravalent dengue vaccine (CYD-TDV), has been licensed as the first dengue vaccine by several 
countries since 2016, the moderate efficacy (56.5-60.8\%) in the presence of neutralizing antibodies (Abs) during its Phase $2 b$ and 3 trials, lower efficacy among dengue naïve compared with dengue experienced individuals (35.5-43.2 vs. $74.3-83.7 \%$ ), and increased risk of hospitalization and severe dengue among young children during the follow-up in years 3-6 highlight the need for a better understanding of immunity, in particular humoral responses, after natural DENV infection (Sabchareon et al., 2012; Capeding et al., 2014; Guy et al., 2015; Hadinegoro et al., 2015; Thomas, 2015; Villar et al., 2015; Aguiar et al., 2016; Flasche et al., 2016; Halstead, 2016; Halstead and Russell, 2016; Wilder-Smith et al., 2016). Recent studies of more than 300 human monoclonal antibodies (mAbs) have led to the discovery of several potent neutralizing epitopes; these together with detailed analysis of polyclonal sera and B-cells after natural infection have provided valuable insights into dengue vaccine development. This review outlines the progress in our understanding of the epitopes and specificity of mouse mAbs, human mAbs and polyclonal sera against DENV surface proteins, the envelope (E) and precursor membrane (prM) proteins, following natural infection; and their implication for new strategies of dengue vaccine to induce more potent neutralizing Abs and less enhancing Abs.

\section{GENOME, VIRION STRUCTURE, ASSEMBLY, AND MATURATION}

The genome of DENV consists of a positive-sense, singlestranded RNA of $10.6 \mathrm{~kb}$ in length. Flanked by the $5^{\prime}$ and $3^{\prime}$ untranslated regions, the single open reading frame encodes a polyprotein precursor, which is cleaved by cellular and viral protease into three structural proteins, the capsid (C), prM, and $\mathrm{E}$, and seven non-structural (NS) proteins, NS1, NS2A, NS2B, NS3, NS4A, NS4B, and NS5 (Murphy and Whitehead, 2011; Pierson and Diamond, 2013).

The E protein, $\sim 55 \mathrm{kDa}$ in size, contains two N-linked glycans and 12 strictly conserved cysteines forming 6 disulfide bridges (Pierson and Diamond, 2013). It contains 495 (DENV1, 2, 4) or 493 (DENV3) amino acids. As the major surface protein present on virions, $\mathrm{E}$ protein participates in virus entry and is the main target of neutralizing and enhancing Abs (Murphy and Whitehead, 2011; Pierson and Diamond, 2013). The ectodomain at the $\mathrm{N}$-terminus contains three distinct domains. Domain I (DI) is located in the center, domain II (DII), an elongated domain containing the fusion loop at its tip, is involved in dimerization and membrane fusion, and domain III (DIII), an immunoglobulin-like domain, is involved in receptor binding and stabilization of trimers during fusion (Modis et al., 2004; Pierson and Diamond, 2013). At the C-terminus, there are two $\alpha$-helices in the stem region and two transmembrane domains in the anchor region (Zhang W. et al., 2003; Pierson and Diamond, 2013).

The prM protein, $\sim 19 \mathrm{kDa}$ in size, contains one $\mathrm{N}$-linked glycan and 6 highly conserved cysteines forming 3 disulfide bridges (Pierson and Diamond, 2013). The prM protein consists of 166 amino acids; during maturation of virions it is cleaved into the pr peptide (91 residues) and membrane (M) protein
(75 residues), which includes an N-terminal loop, an $\alpha$ helical domain, and two transmembrane domains (Pierson and Diamond, 2013; Zhang et al., 2013). After biosynthesis, prM protein forms a heterodimer with $\mathrm{E}$ protein to function as a chaperone for $\mathrm{E}$ protein and prevent premature fusion of $\mathrm{E}$ protein within acidic compartments along the secretory pathway (Mukhopadhyay et al., 2005; Pierson and Diamond, 2013).

DENV enters the cell through receptor mediated endocytosis. The low-pH environment in endosome results in conformational change of $\mathrm{E}$ protein and fusion between viral and endosomal membranes (Modis et al., 2004; Mukhopadhyay et al., 2005; Kielian and Rey, 2006; Pierson and Diamond, 2013). The assembly of DENV occurs in the membranes derived from rough ER, where the immature virions bud into the lumen of ER and transport through the secretary pathway (Mukhopadhyay et al., 2005; Pierson and Diamond, 2013). Within the low $\mathrm{pH}$ environment of trans-Golgi the prM protein on immature virions is cleaved by furin or furin-like protease into $\mathrm{pr}$ peptide and $\mathrm{M}$ protein; $\mathrm{pr}$ is released under neutral $\mathrm{pH}$ in the culture medium to form mature particles (Perera and Kuhn, 2008; Yu et al., 2008). However, the prM cleavage is inefficient, leading to a mixture of mature, immature and partially immature DENV particles in tissue culture (Cherrier et al., 2009; Junjhon et al., 2010). Cryo-EM studies have revealed structural details of mature and immature DENV particles as shown in Figure 1.

\section{DENV PROTEINS RECOGNIZED BY ABS AFTER DENV INFECTION}

Following primary DENV infection, individuals develop an IgM response, followed by an IgG response. After secondary DENV infection, individuals develop a greater IgG response compared to IgM response (Innis, 1997; Vaughn et al., 1999). IgM response is relevant to dengue diagnosis, whereas IgG response is critical to pathogenesis, protection or enhancement, and vaccine development.

Different assays have been employed to study Abs response after DENV infection, including enzyme-linked immunosorbent assay (ELISA), Western blot (WB) and microsphere immunoassay to examine binding Abs, as well as neutralization and enhancing assays for functional Abs. Most binding assays, which use either DENV virions or recombinant $\mathrm{E}$ protein as antigen, provide little information on Abs targeting different DENV proteins, whereas WB analysis that employs antigens derived from DENV-infected cells can detect Abs responses to individual DENV proteins and their relative abundance. Early studies reported E, NS3, and NS5 proteins were recognized (Churdboonchart et al., 1991; Se-Thoe et al., 1999; Valdes et al., 2000). Later studies revealed that the strongest Abs response was anti-E Abs which recognize both the infecting DENV serotype and three other serotypes plus West Nile virus (WNV), a member of Japanese encephalitis virus (JEV) serocomplex, followed by anti-prM and anti-NS1 Abs after primary DENV infection (Figure 2A). Following secondary infection, strong cross-reactive anti-E Abs plus 
A

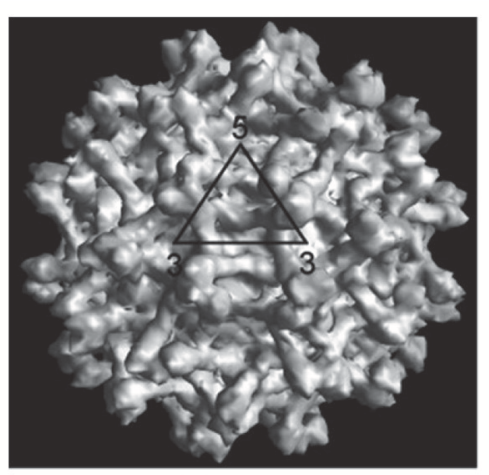

B

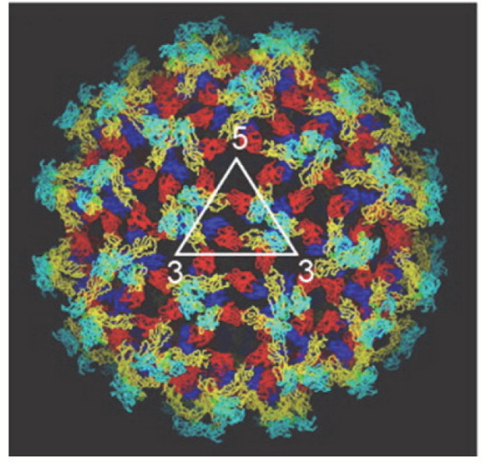

C

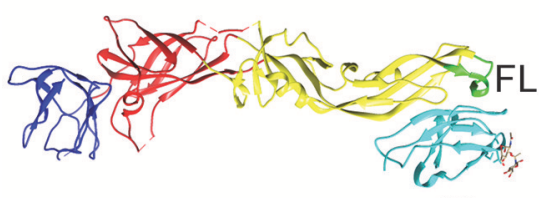

D

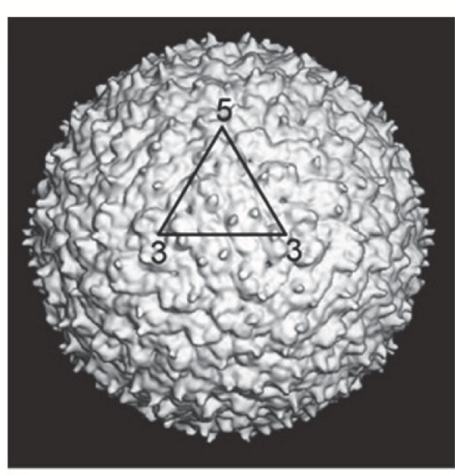

E

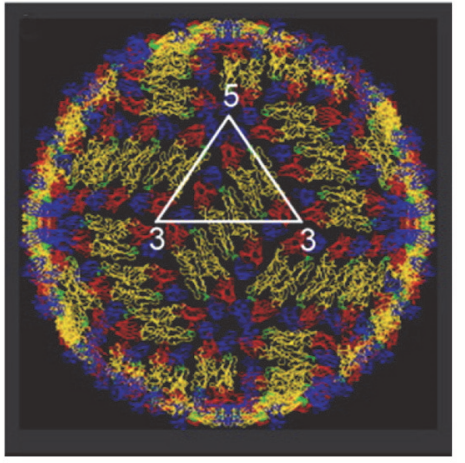

F

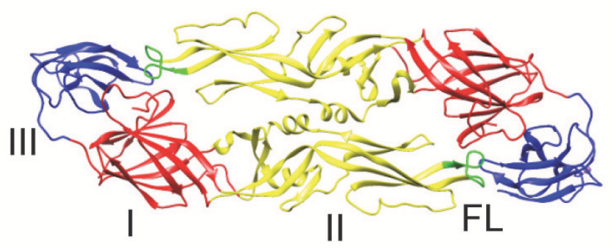

FIGURE 1 | Immature and mature DENV particles. Immature particles: (A) Cryo-EM picture showed spiky surface, formed by 60 trimeric prM-E heterodimers. (B) Pseudoatomic structure showed pr peptide (cyanine) and fusion loop (FL, green) on surface (Zhang Y. et al., 2003; Perera et al., 2008). (C) X-ray crystal structure of prM-E heterodimers showed pr peptide (cyanine) and FL (green) exposed on each spike (Li et al., 2008). Mature particles: (D) Cryo-EM picture showed smooth surface with 90 E dimers in herringbone pattern. (E) Pseudoatomic structure showed poorly exposed FL (green) (Kuhn et al., 2002; Perera et al., 2008). (F) X-ray crystal structure of E protein ectodomain (E-E dimers) revealed DI (red), DIl (yellow) with its FL (green), and DIII (blue) (Modis et al., 2004). (A,B,D,E with permission from the authors of Perera et al., 2008; C,F generated by the program UCSF Chimera).

anti-prM and anti-NS1 Abs were found (Figure 2B) (Lai et al., 2008; Tsai et al., 2015). A similar trend was observed in vaccinees following primary and secondary immunization with monovalent live-attenuated DENV vaccines (Figures 2C,D). Together, these observations suggest that cross-reactive anti-E Abs are the major Abs, followed by anti-prM and NS1 Abs.

\section{DIFFERENT CATEGORIES OF ANTI-E MABS: BINDING SPECIFICITY AND EPITOPES}

In the genus Flavivirus of the family Flaviviridae, members belonging to different serocomplexes cause significant human diseases, including the four serotypes of DENV in the DENV serocomplex, WNV and JEV in the JEV serocomplex, tickborne encephalitis virus (TBEV) in the TBEV serocomplex, YFV as a single member, and Zika virus (ZIKV) in its serocomplex (Pierson and Diamond, 2013). The amino acid sequence homology of $\mathrm{E}$ protein is about $39-49 \%$ between different serocomplexes, 63-78\% between DENV serotypes, and up to $96-97 \%$ between genotypes within each DENV serotype (Stiasny et al., 2006). Based on the binding specificity, anti-E Abs that recognize members of two or more serocomplexes, members within the same serocomplex, or a single member are categorized as group-reactive, complex-reactive, and type-specific Abs, respectively (Calisher et al., 1989). Determining the binding specificity of anti-DENV Abs provides important information on the extent of cross-reactivity to different flaviviruses, but this requires the inclusion of $4 \mathrm{DENV}$ serotypes and other flaviviruses as antigens in the binding assay. Most studies utilized antigens 


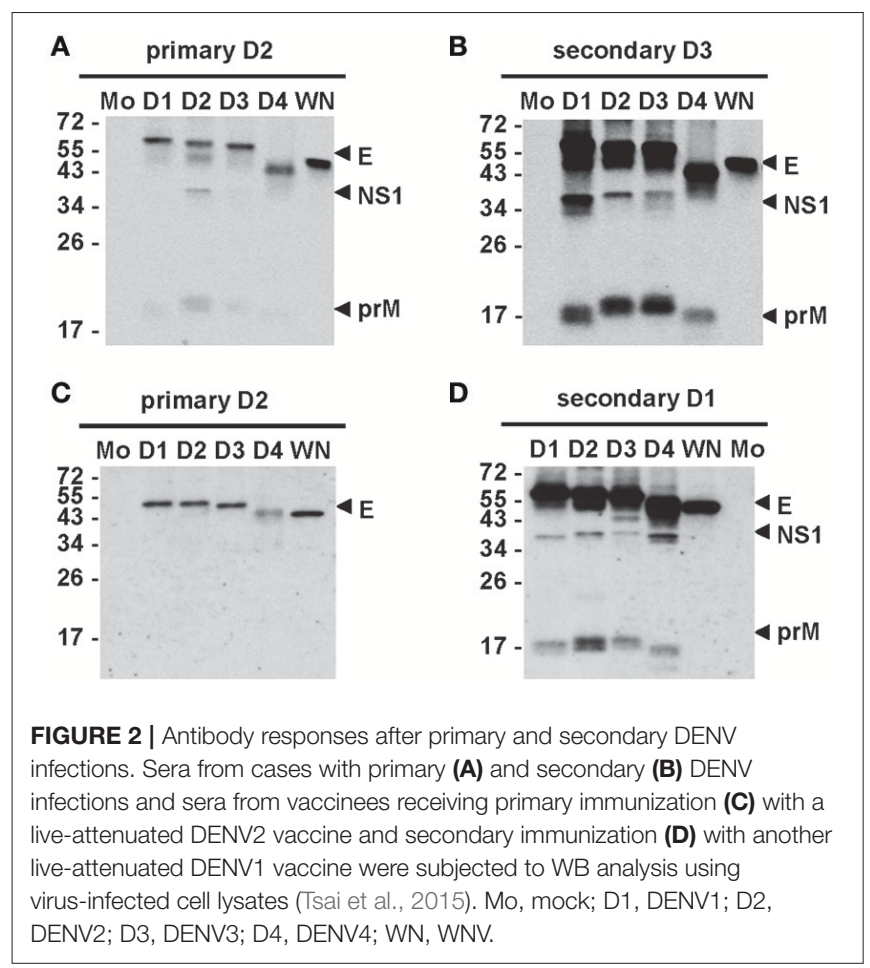

from 4 serotypes only and classified anti-DENV Abs as typespecific and cross-reactive Abs, which include both complexreactive and group-reactive Abs.

DENV E protein contains both linear and discontinuous epitopes. Linear epitopes can be identified by peptide-scan ELISA; discontinuous epitopes can be identified by alaninescanning or shortgun mutagenesis, yeast or phage-display library, neutralization escape mutant, and cryo-EM analysis of Fab and virions. Although a few linear epitopes on $\mathrm{E}$ protein have been reported based on peptide ELISA of dengue-immune sera (Aaskov et al., 1989; Megret et al., 1992; da Silva et al., 2009), the majority of anti-E Abs likely recognize discontinuous and conformational epitopes. The evidence came from studies of mouse anti-E mAbs and anti-E Abs in human sera, in which most lost binding in WB analysis under reducing condition and were thus sensitive to the conformation provided by disulfide bridges (Megret et al., 1992; Roehrig et al., 1998; Lai et al., 2008). Consistent with this, a mutational study revealed that the 6 disulfide bridges formed by 12 cysteines were critical for the epitope expression and conformation of DENV E protein (Roehrig et al., 2004).

\section{EPITOPES RECOGNIZED BY MOUSE ANTI-E MABS}

Studies of mouse mAbs against DENV have shown that different categories of anti-E mAbs have different epitopes and neutralizing potency. Group-reactive mAbs primarily recognize the highly conserved residues in the fusion loop of DII, whereas complex-reactive and type-specific mAbs recognize different but slightly overlapping residues in DIII (Crill and Chang, 2004; Gromowski and Barrett, 2007; Gromowski et al., 2008; Lin et al., 2012). The neutralizing potency of type-specific mAbs was generally higher than that of complex-reactive mAbs, which in turn was higher than that of group-reactive mAbs (Gromowski and Barrett, 2007; Sukupolvi-Petty et al., 2007; Gromowski et al., 2008). Several type-specific anti-DIII potent neutralizing $\mathrm{mAbs}\left(\mathrm{NT}_{50}\right.$ in the range of $\mathrm{ng} / \mathrm{ml}$ ) have been reported as potential therapeutic mAbs (Brien et al., 2010; Shrestha et al., 2010; Sukupolvi-Petty et al., 2010, 2013). It should be noted that these potent neutralizing mAbs were generated by an immunization protocol including two DENV infections in the IFN- $\alpha / \beta$ receptor-deficient (IFN- $\alpha \beta \mathrm{R}^{-/-}$) strain in the C57BL/ 6 background followed by boost with recombinant DIII (rDIII), which was different from early protocols using DENV to immunize wild type (WT) BALB/c mice (Gromowski and Barrett, 2007; Sukupolvi-Petty et al., 2007; Lin et al., 2012). More than 200 mouse anti-E mAbs including several potent neutralizing mAbs are summarized in Table $\mathbf{1}$.

Several in-depth studies of mouse anti-E mAbs against DENV and WNV have provided critical insights into the mechanisms of neutralization including the stoichiometry (Pierson et al., 2007), maturation status (Nelson et al., 2008), temperature (Dowd et al., 2011), step of fusion (Thompson et al., 2009), genotype/strain difference (Austin et al., 2012; Sukupolvi-Petty et al., 2013), type-specific or cross-neutralization (Cockburn et al., 2012a,b; Midgley et al., 2012), structural organization, and "breathing" on virion (Lok et al., 2008; Edeling et al., 2014).

\section{EPITOPES RECOGNIZED BY HUMAN ANTI-E MABS}

Several technologies including EBV-immortalization of B cells, cytofusion-hybridoma, and single cell-expression cloning of plasmablasts (Wilson and Andrews, 2012) have been employed to generate human mAbs against DENV after natural infection or vaccination (Beltramello et al., 2010; de Alwis et al., 2011, 2012; Smith et al., 2012, 2013a,b, 2014; Teoh et al., 2012; Xu et al., 2012; Costin et al., 2013; Tsai et al., 2013; Dejnirattisai et al., 2015; Priyamvada et al., 2016). Table 2 summarizes more than 300 human anti-E mAbs reported thus far. Despite different methods/antigens were used to generate and characterize these mAbs, predominant cross-reactive mAbs were identified from individuals after primary and secondary DENV infection, whereas type-specific mAbs were identified mainly from individuals after primary infection.

Based on the binding to recombinant E protein, DIII or DI/II, alanine mutants, yeast library or escape mutants, group-reactive $\mathrm{mAbs}$ were found to recognize either residues in fusion loop or both fusion loop and bc loop, a loop next to fusion loop in DII (Costin et al., 2013; Smith et al., 2013a; Tsai et al., 2013), typespecific mAbs recognize epitopes in DIII, interdomain residues, DI/II hinge region or quaternary epitopes on virion (Beltramello et al., 2010; de Alwis et al., 2011, 2012; Teoh et al., 2012; Fibriansah et al., 2014, 2015a,b), and complex-reactive mAbs recognize DIII or E-dimer epitope which involves fusion loop 
TABLE 1 | Summary of mouse anti-E mAbs reported in four large studies.

\begin{tabular}{|c|c|c|c|c|c|c|c|}
\hline \multirow{2}{*}{$\begin{array}{l}\text { Immunogen }^{\mathbf{a}} \\
\text { DENV1 }\end{array}$} & \multirow{2}{*}{$\begin{array}{l}\text { \# of } \\
\text { mAbs } \\
67\end{array}$} & \multirow{2}{*}{$\begin{array}{l}\text { Specificity } \\
\text { TS/CrR[CR+GR] } \\
30 \mathrm{TS}(45 \%) \\
30 \mathrm{CrR}(45 \%) \\
7 \mathrm{ND}\end{array}$} & \multicolumn{2}{|c|}{$\begin{array}{l}\text { Binding } \\
\text { DI/II DIII E }\end{array}$} & \multirow{2}{*}{$\begin{array}{l}\text { Epitopes }^{\mathbf{d}} \\
\text { DIII: Ir, str A and str G }\end{array}$} & \multirow{2}{*}{$\begin{array}{l}\text { Potent NT mAbs } \\
\text { or remarks }^{\text {e }} \\
15 \text { strong NT mAbs } \\
14 \text { anti-DIII }\end{array}$} & \multirow{2}{*}{$\begin{array}{l}\text { References } \\
\text { Shrestha et al., } 2010\end{array}$} \\
\hline & & & $\begin{array}{l}5 \\
5 \\
4\end{array}$ & $\begin{array}{l}25 \\
25 \\
3\end{array}$ & & & \\
\hline DENV2 & 33 & $\begin{array}{l}20 \text { TS }(61 \%) \\
11 \mathrm{CrR}(33 \%) \\
2 \mathrm{ND}\end{array}$ & $\begin{array}{l}8 \\
6 \\
2\end{array}$ & $\begin{array}{l}11 \\
1 \\
5\end{array}$ & $\begin{array}{l}\text { DIII: Ir, CCL and str A, DI: Ir, } \\
\text { DIl: Ir, di and FL }\end{array}$ & $\begin{array}{l}24 \text { strong NT mAbs } \\
11 \text { anti-DIII, } 13 \\
\text { anti-DI/DII }\end{array}$ & Sukupolvi-Petty et al., 2010 \\
\hline DENV3 & 74 & $\begin{array}{l}48 \text { TS }(65 \%) \\
24 \text { CrR }(32 \%) \\
2 \text { ND }\end{array}$ & $\begin{array}{l}13 \\
15 \\
2\end{array}$ & $\begin{array}{l}25 \\
10 \\
4 \\
5\end{array}$ & DIII: Ir, str A and str G & $\begin{array}{l}22 \text { strong NT mAbs } \\
19 \text { anti-DIII }\end{array}$ & Brien et al., 2010 \\
\hline DENV4 & 47 & $\begin{array}{l}26 \text { TS }(55 \%) \\
17 \text { CrR }(36 \%) \\
4 \text { ND }\end{array}$ & $\begin{array}{l}6 \\
9 \\
2\end{array}$ & $\begin{array}{l}13 \\
7 \\
5 \\
3 \\
2\end{array}$ & DIII: Ir, CCL, str F and str G & $\begin{array}{l}6 \text { strong NT mAbs } \\
5 \text { anti-DIII }\end{array}$ & Sukupolvi-Petty et al., 2013 \\
\hline
\end{tabular}

aImmunization protocol: IFN- $\alpha \beta R^{-/-}$C57BL/6 mice infected with DENV twice, and boosted with rDIII once.

The method of generating mouse mAbs was the same, including isolation of splenocytes, hybridoma and

screening by flow cytometry with DENV-infected cells.

${ }^{b} T S$ : type-specific, CrR: cross-reactive, CR: complex-reactive, GR: group-reactive.

${ }^{c}$ Binding to recombinant DI/II or DIII of E protein or E protein, ND: not done.

IIr: lateral ridge, str: strand, CCL: CC' loop, di: dimer interface, FL: fusion loop.

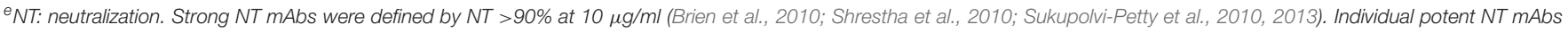

$\left(N T_{50}<0.5 \mu \mathrm{g} / \mathrm{ml}\right)$ are not listed.

and other residues (Beltramello et al., 2010; de Alwis et al., 2011; Dejnirattisai et al., 2015). The quaternary epitopes recognized by several type-specific potent neutralizing mAbs $(14 \mathrm{C} 10,1 \mathrm{~F} 4$, 2D22, and 5F7) are shown in Figures 3A-D (Teoh et al., 2012; Fibriansah et al., 2014, 2015a,b); the E-dimer epitopes 1 and 2 recognized by complex-reactive potent neutralizing $\mathrm{mAbs}$ are shown in Figure 3E (Rouvinski et al., 2015).

\section{EPITOPES RECOGNIZED BY ANTI-PRM MABS}

After the early reports of some mouse anti-prM mAbs (Megret et al., 1992; Roehrig et al., 1998), a large panel of human anti-prM $\mathrm{mAs}$ were found to be cross-reactive, weakly or non-neutralizing, and enhance DENV in Fc $\gamma$ R cells, suggesting anti-prM response is detrimental (Dejnirattisai et al., 2010). Consistent with this, mouse anti-prM mAbs were reported to cause antibodydependent enhancement (ADE) in vitro, especially for immature or partially immature DENV (Rodenhuis-Zybert et al., 2010). Since fusion loop epitopes were more exposed on immature DENV, anti-fusion loop mAbs were shown to preferentially bind immature DENV (Cherrier et al., 2009), enhance their infectivity in vitro (Rodenhuis-Zybert et al., 2011), and cause ADE in vivo, including monkey (Goncalvez et al., 2007) and lethal disease in AG129 mice (Shresta et al., 2006; Balsitis et al., 2010; Zellweger et al., 2010).

The epitopes of mouse anti-prM mAbs were previously reported in a conserved region of pr peptide (residues 53-67) (Huang et al., 2006). A recent study of 25 human anti-prM mAbs revealed several overlapping epitopes within a major antigenic site in the pr peptide; a few anti-prM mAbs can recognize $\mathrm{E}$ protein as well (Chan et al., 2012; Smith et al., 2015).

\section{DIFFERENT CATEGORIES OF ANTI-E ABS IN POLYCLONAL HUMAN SERUM}

Previously, depletion of human sera with antigen derived from non-infecting DENV serotypes, so called heterologous serotypes, reported that the majority of anti-E Abs after primary infection was cross-reactive and a minor proportion was type-specific (Lai et al., 2008). This was supported by studies using WT and mutant virus-like particles (VLPs) containing mutations of cross-reactive epitopes to measure the endpoint ELISA titers and determine the proportion of cross-reactive and type-specific Abs (Crill et al., 2009; Lai et al., 2013). Another study using rDIII in depletion revealed the proportion of type-specific anti-DIII Abs was $0.4-8.1 \%$ after primary DENV infection (Wahala et al., 2009). Interestingly, an integrated analysis of 319 human anti-E mAbs from 7 studies in Table 2, of which each contained a panel of (rather than one or two) human mAbs to represent the $\mathrm{Ab}$ repertoire in the study subjects, revealed that the percentages of cross-reactive vs. type-specific mAbs derived from primary and secondary DENV infections were 76.8 vs. $23.2 \%$ and 97 vs. $3 \%$, respectively (Table 3 ). Consistent with this, a recent study using multicolor fluorospot assay to examine memory B cell population reported that the percentages of cross-reactive vs. type-specific Bcell clones after primary and secondary infections were 52 vs. $48 \%$ and 98 vs. $0.2-2 \%$, respectively (Hadjilaou et al., 2015). 
TABLE 2 | Summary of human anti-E mAbs reported in literature.

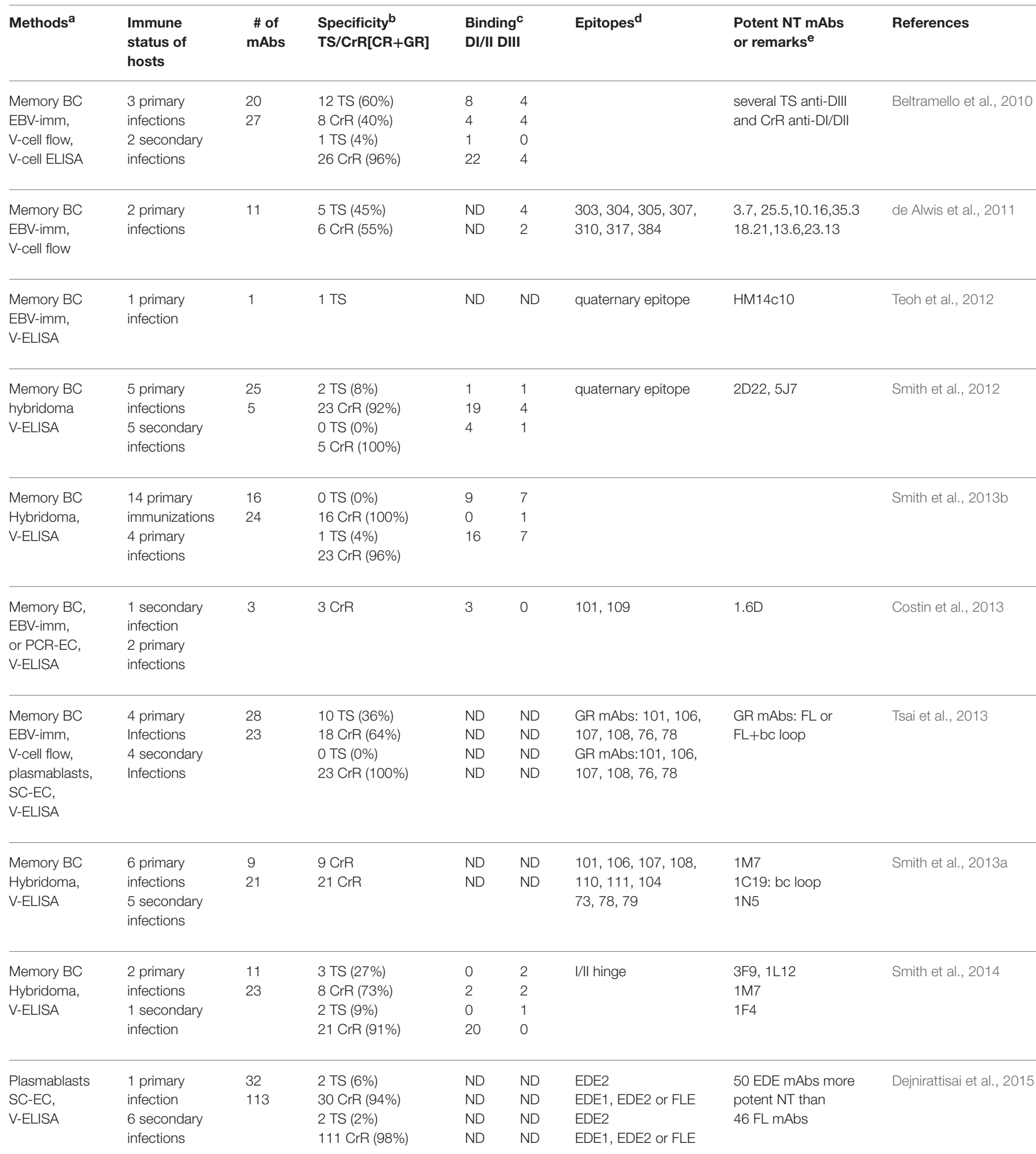

${ }^{a} B C, B$-cells; EBV-imm, Epstein-Barr virus immortalization; V-cell flow, screen by flow cytometry using virus-infected cells; V-cell ELISA, screen by ELISA using virus-infected cells; $V$-ELISA, screen by ELISA using virion, PCR-EC; PCR expression cloning of Ig genes; SC-EC, Single-cell PCR expression cloning of Ig genes.

${ }^{b} T S$, type-specific; $C r R$, cross-reactive; $C R$, complex-reactive; GR, group-reactive.

${ }^{c}$ Binding to recombinant DI/II or DIII of E protein, ND: not done.

${ }^{a}$ Major epitopes identified are listed. EDE, E dimer epitope; FLE, fusion loop epitope (Dejnirattisai et al., 2015).

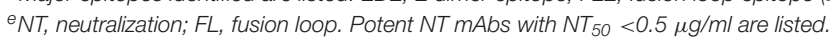


A $14 \mathrm{c} 10$

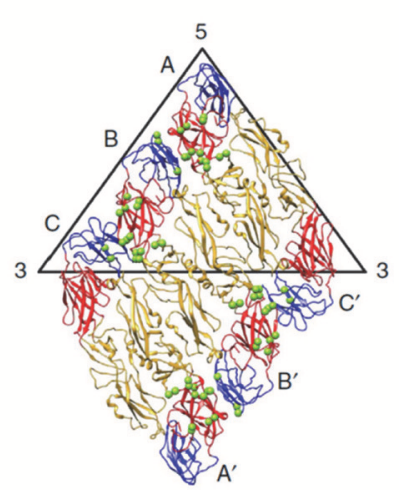

D 2D22

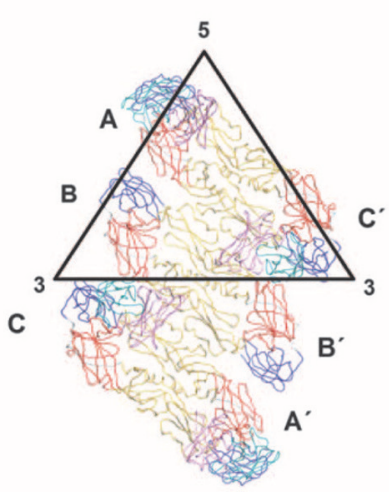

B 1F4

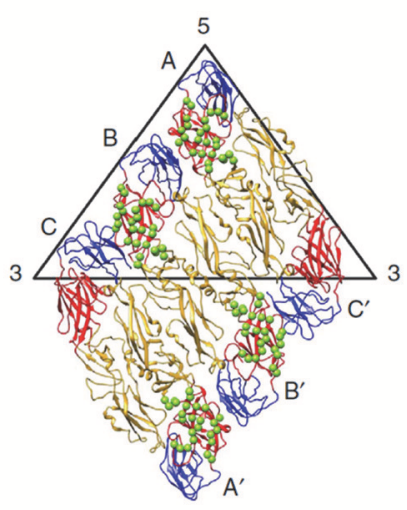

E EDE1 (C10)

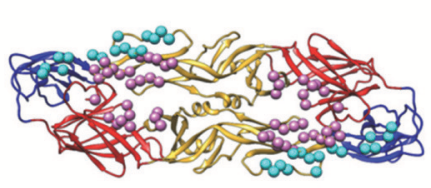

EDE2 (B7)

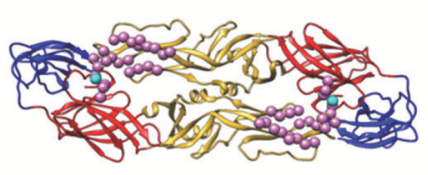

FIGURE 3 | Epitopes recognized by potent human anti-E mAbs. (A) DENV1- type specific (TS) mAb (14c10) recognizes quaternary epitopes involving DI, DII, and DIII on virion (Teoh et al., 2012). (B) Another DENV1-TS mAb (1F4) recognizes monomeric DI/ll hinge present on virion (de Alwis et al., 2012; Fibriansah et al., 2014; Smith et al., 2014). (C) DENV3-TS mAb (5F7) recognizes quaternary epitopes involving DI, DII, and DIII on virion (de Alwis et al., 2012; Smith et al., 2012; Fibriansah et al., 2015b). (D) DENV2-TS mAb (2D22) recognizes quaternary epitopes involving DI, DIl and DIII on virion (de Alwis et al., 2012; Smith et al., 2012; Fibriansah et al., 2015a). (E) cross-reactive mAbs C10 and B7 recognize E-dimer epitope 1 (EDE1) and E-dimer epitope 2 (EDE2), respectively; both involve fusion loop and other residues on virion (Dejnirattisai et al., 2015; Fibriansah et al., 2015a; Rouvinski et al., 2015). (Panels A-E with permission from the authors of Fibriansah et al., 2015a,b).

TABLE 3 | Relationship between the specificity of human anti-E mAbs and immune status of hosts.

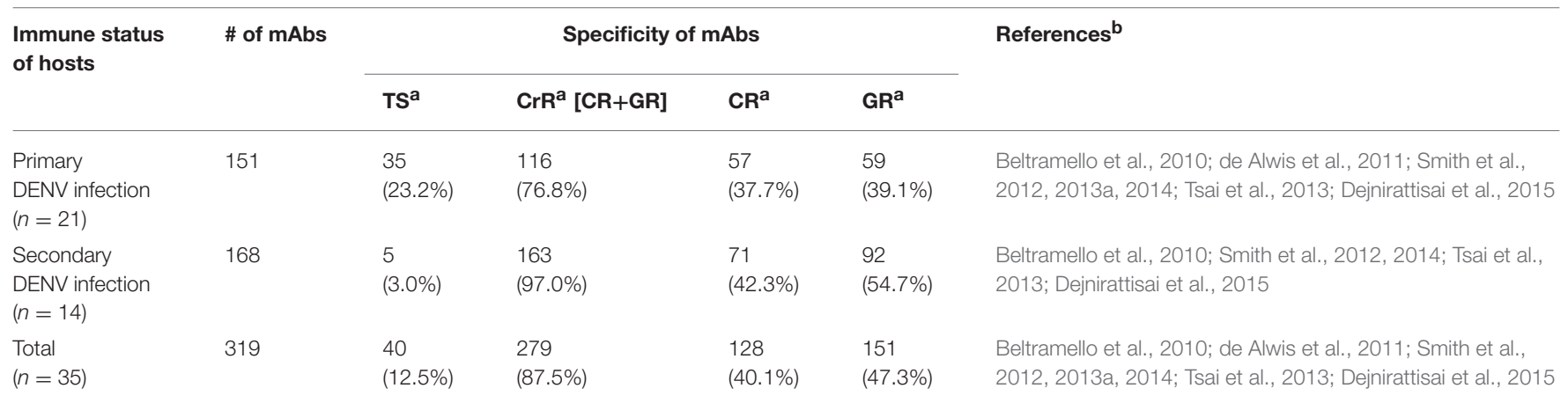

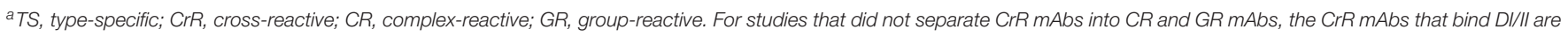
considered GR mAbs and those bind DIII are considered CR mAbs in this analysis.

bStudies in Table 2 that characterized the binding specificity of a panel of human mAbs derived from individuals with known DENV immune status were included in the analysis. 


\section{EPITOPES RECOGNIZED BY NEUTRALIZING ANTI-E ABS IN POLYCLONAL SERUM}

It is known that following primary DENV infection, individuals develop monotypic neutralizing Abs against the infecting serotype, which correlate with the long-lived protection against that serotype (Sabin, 1952; Innis, 1997; Halstead, 2003; Imrie et al., 2007). After recovery from secondary infection, individuals develop multitypic neutralizing Abs not only against the previously exposed serotypes but also against the serotypes to which they have not yet been exposed ("non-exposed" serotypes) (Innis, 1997; Halstead, 2003). Such heterotypic neutralizing Abs are thought to contribute to protection against the nonexposed serotypes during the third or fourth DENV infections, as suggested by the lower rates of hospital admission (Gibbons et al., 2007) and reduced risk of symptomatic DENV infection in humans (Olkowski et al., 2013) as well as lower viremia in monkeys (references in Tsai et al., 2013).

Several studies have investigated the nature of anti-E Abs contributing to neutralizing activities after DENV infection. In the situation of primary infection, an initial study reported that rDIII cannot deplete the monotypic type-specific neutralizing activity after primary infection, suggesting that anti-DIII Abs do not contribute to such neutralizing activity (Wahala et al., 2009). A second study showed that DENV virions of the infecting serotype rather than those of the non-exposed serotypes or recombinant $\mathrm{E}$ proteins can deplete the monotypic typespecific neutralizing activity, suggesting that type-specific antiE Abs recognizing epitopes present on virions contribute to such neutralizing activity (de Alwis et al., 2012). Analysis of the escape mutants of 3 potent TS human mAbs (1F4, 2D22, and 5F7) that bind to virions revealed their epitopes on the DI/II hinge region or DIII (de Alwis et al., 2012), which was further verified by cryo-EM studies (Fibriansah et al., 2014, 2015a,b) (Figures 3B-D). A study of vaccinees reported reduced neutralization sensitivity to mutant (E126K/E157K) DENV1 replicon particles in 18 (77\%) of 24 vaccinees receiving liveattenuated DENV1 vaccine, suggesting anti-E Abs in polyclonal serum recognizing these two residues proximal to the DI/II hinge contribute to the type-specific neutralizing activities (VanBlargan et al., 2013). This was followed by a series of studies using chimeric viruses, in which the candidate epitope residues on E protein were replaced by those of other serotypes. A study of chimeric virus containing $25 \mathrm{DI} / \mathrm{II}$ hinge residues of DENV4 in the DENV3 backbone (rDENV3/4) reported loss of neutralization in 4 primary DENV3 sera and gain of neutralization in 4 primary DENV4 sera (Messer et al., 2014), though the article was retracted due to contamination of rDENV3/4 virus stock (Messer et al., 2015). A second study using chimeric virus containing 40 DIII residues of DENV2 in the DENV4 backbone (rDENV4/2) revealed gain of neutralization in 7 primary DENV2 sera and no loss of neutralization in 4 primary DENV4 sera, suggesting these residues contribute to type-specific neutralizing activity after primary DENV2 but not DENV4 infection (Gallichotte et al., 2015). A recent study using chimeric virus containing $25 \mathrm{DI} / \mathrm{II}$ hinge residues of DENV3 in the DENV4 backbone (rDENV4/3) revealed $>60 \%$ loss of neutralization in 3 out of 6 primary DENV4 sera and all 4 vaccinees receiving live-attenuated DENV4 vaccine, suggesting these residues contribute to type-specific neutralizing activity after primary DENV4 infection/immunization (Nivarthi et al., 2017).

Taken together, these studies suggest that type-specific Abs recognizing residues proximal to DI/II hinge, DIII complex epitope residues, and DI/II hinge residues contribute to type-specific neutralizing activity following primary DENV1 immunization, primary DENV2 infection/immunization, and primary DENV4 infection/immunization, respectively (VanBlargan et al., 2013; Gallichotte et al., 2015; Nivarthi et al., 2017). It is worth noting that type-specific neutralizing Abs in $23 \%$ of individuals after primary DENV1 immunization do not recognize residues proximal to DI/II hinge, suggesting the presence of other type-specific neutralizing epitope in some DENV1 vaccinees (VanBlargan et al., 2013). Similarly, $32 \%$ of type-specific neutralizing Abs after primary DENV2 infection/immunization recognize DIII residues alone, suggesting the presence of type-specific neutralizing epitopes other than DIII complex epitope in DENV2 immune serum (Gallichotte et al., 2015). The observation that $50 \%$ (3 out of 6 ) of individuals after primary DENV4 infection do not recognize the DI/II hinge residues suggests the presence of other type-specific neutralizing epitopes in DENV4 immune serum (Nivarthi et al., 2017). This is in agreement with the reports of individual variations in the specificity of anti-E Abs to different domains and their contribution to neutralizing activities in polyclonal sera after YFV vaccination and TBEV infection/immunization (Vratskikh et al., 2013; Jarmer et al., 2014).

In the situation of secondary DENV infection, it was reported that group-reactive anti-E mAbs derived from patients after secondary DENV infection had higher binding avidity and neutralizing potency compared with those derived after primary infection, suggesting cross-reactive anti-E Abs (including groupreactive and complex-reactive Abs) evolved from low avidity and poor neutralizing after primary infection to high avidity and potent neutralizing after secondary infection (Tsai et al., 2013). A recent study using a two-step depletion protocol to remove group-reactive and complex-reactive anti-E Abs revealed that cross-reactive anti-E Abs contributed significantly to neutralizing activities against both exposed and non-exposed DENV serotypes after secondary DENV infection/immunization (Tsai et al., 2015).

\section{EPITOPES RECOGNIZED BY ENHANCING ABS IN POLYCLONAL SERUM}

Previous epidemiological studies have shown that individuals experiencing a secondary DENV infection had a significant higher risk of severe disease than those experiencing primary infection (Halstead, 1988 and references in). In the presence of diluted dengue immune serum, DENV replicates to produce higher titers of virus particles in human $\mathrm{Fc} \gamma$ receptorbearing cells compared with that in the absence of serum, a phenomenon known as ADE (Halstead and O'Rourke, 1977; 
Halstead, 1988, 2003). Further studies have shown that ADE is a concentration-dependent phenomenon and can be caused by both non-neutralizing $\mathrm{mAbs}$ and neutralizing $\mathrm{mAbs}$ at suboptimal concentration (Pierson et al., 2007, 2008; Nelson et al., 2008), including very potent human neutralizing mAbs (Beltramello et al., 2010; Teoh et al., 2012; Fibriansah et al., 2014, 2015a,b; Dejnirattisai et al., 2015). Thus, induction of potent and durable neutralizing Abs has been a goal of DENV vaccine development (Murphy and Whitehead, 2011; Schwartz et al., 2015).

Using depletion protocol together with K562 cell-based ADE assay and mouse model, a recent study demonstrated that removal of cross-reactive Abs in primary DENV-immune sera ablated ADE in vitro and in vivo (de Alwis et al., 2014). Moreover, both recombinant E-specific Abs (including fusion loop Abs) and anti-prM Abs were shown to contribute significantly to ADE in vitro.

\section{T-CELL RESPONSES AFTER NATURAL DENV INFECTION}

T-cell responses after DENV infection and their role in protection or pathogenesis have been reviewed previously (Rothman, 2011; Weiskopf and Sette, 2014). Early studies of T-cell responses during acute DENV infection in patients with different disease severity suggested cross-reactive CD8 T-cells contribute to pathogenesis rather than protection (Mongkolsapaya et al., 2003; Duangchinda et al., 2010). However, other studies reported that the timing of T-cell response does not match with plasma leakage, a key feature of DHF/DSS (Dung et al., 2010). Recent studies suggested protective roles of CD8 T-cells response and the association of multifunctional CD8 T-cells with protection against disease in a Sri Lankan population (Weiskopf et al., 2013; references in Rothman, 2011). To further address the role of Tcells in protection or pathogenesis, investigating the pre-existing $\mathrm{T}$-cell response and disease outcome in well-designed prospective cohorts is needed (Rothman, 2011).

Since CD8 T-cell epitopes were mapped primarily to NS proteins such as NS3 and NS5 (Mathew et al., 1996; Weiskopf et al., 2013, 2015), the moderate efficacy of CYD-TDV vaccine has been attributed to the lack of NS proteins of DENV to elicit CD8 T-cell responses (Thomas, 2015; Halstead and Russell, 2016). It is worth noting that structural proteins (C, prM and E) do contain CD8 T-cell epitopes (Mathew et al., 1996; Weiskopf et al., 2013, 2015) and T-cell response to DENV structural proteins has been shown in naïve individuals receiving CYDTDV vaccine (Harenberg et al., 2013). Subunit candidate vaccine containing recombinant DENV E protein can induce T-cell response based on IFN $\gamma$ ELISPOT assays (Manoff et al., 2015). Moreover, two successful flavivirus vaccines (JEV and TBEV vaccines) are based on inactivated virions in the absence of NS proteins (Ishikawa et al., 2014). Although it remains to be investigated whether NS proteins are required to be a component of dengue vaccine, evaluation of dengue vaccine in clinical trials should include the assessment of T-cell responses (Rothman et al., 2015).

\section{IMPLICATION FOR VACCINE STRATEGY}

Several candidate dengue vaccines are currently in different phases of clinical trials, including various formats such as live attenuated virus, purified inactivated virus, recombinant $\mathrm{E}$ protein, and DNA vaccine (Guzman and Harris, 2015; Schwartz et al., 2015). The goals are to provide long-lasting protection against each of the four serotypes, good safety profile, welltolerated reactogenicity, suitable regimen for target population and affordable cost (Murphy and Whitehead, 2011). Following the reports of the Phase $2 \mathrm{~b}$ and 3 trials of CYD-TDV vaccine and its subsequent licensure, several comments and reviews have been published regarding the population benefits and potential risks of this vaccine (Thomas, 2015; Halstead, 2016; Halstead and Russell, 2016; Wilder-Smith et al., 2016), implication to dengue immunopathogenesis (Screaton et al., 2015), complexity of vaccine and assays for evaluation (Flipse and Smit, 2015), and comparison with another promising candidate vaccine (Whitehead, 2016).

Both Abs and T-cell response contribute to protection and clearance of DENV infection. From the observations of natural DENV infection, reduction in DHF/DSS during early infancy less than 6 months, and passive Abs transfer experiments in animals, neutralizing Abs likely play a major role in protection (review by Murphy and Whitehead, 2011). However, non-neutralizing Abs and neutralizing Abs at suboptimal concentrations can cause $\mathrm{ADE}$ in vitro and in vivo (Goncalvez et al., 2007; Pierson et al., 2007, 2008; Nelson et al., 2008; Balsitis et al., 2010; Zellweger et al., 2010; Murphy and Whitehead, 2011). Thus, induction of durable potent neutralizing Abs and less enhancing Abs has been a goal of DENV vaccine development (Murphy and Whitehead, 2011; Schwartz et al., 2015). In this regard, the discovery of epitopes recognized by potent neutralizing mAbs following natural DENV infection have important implication for dengue vaccine development. These potent neutralizing epitopes include DIII, DI/II hinge region, quaternary epitopes on virion, Edimer epitope, and fusion loop epitope recognized by human mAbs after secondary infection. The identification of epitopes recognized by mAbs that are weakly or non-neutralizing and enhancing, such as anti-prM mAbs, have implication for new strategy of dengue vaccine as well.

Previous reports of potent neutralizing anti-DIII mAbs in mice suggest DIII can be a potential vaccine candidate (Brien et al., 2010; Shrestha et al., 2010; Sukupolvi-Petty et al., 2010, 2013). While anti-DIII Abs represent only a small percentage of total anti-E Abs and do not contribute greatly to neutralizing activities in human sera (Crill et al., 2009; Wahala et al., 2009; Gallichotte et al., 2015), these observations do not preclude rDIII from being a vaccine candidate. This is because a number of potent neutralizing anti-DIII mAbs were also found in humans (Beltramello et al., 2010; de Alwis et al., 2011), suggesting such neutralizing Abs can be induced during natural DENV infection. Notably, an elegant study of WNV vaccine in mice showed that rDIII induced much lower neutralizing Abs compared with inactivated virions, whereas inactivated virions boosted with rDIII induced highest neutralizing Abs (Zlatkovic et al., 2011). How to induce high titers of neutralizing Abs by rDIII 
remains to be explored for the development of a subunit DENV vaccine.

The discovery of quaternary epitopes that are recognized by type-specific human potent neutralizing mAbs (14c10, 1F4, 2D22, and 5J7) suggests the importance of conformation and arrangement of E protein on virions (or VLPs) to induce potent neutralizing Abs (Teoh et al., 2012; Fibriansah et al., 2014, 2015a,b). Notably, mAb 1F4 recognizes residues in DI/II hinge of an $\mathrm{E}$ monomer but cannot bind recombinant $\mathrm{E}$ protein, which primarily forms monomer at the concentration tested in the binding assay (Fibriansah et al., 2014). The difference in the angle of DI/II between virions and solution is likely to explain such discrepancy. In light of the observation that anti-prM mAbs are weakly or non-neutralizing and cause ADE (Huang et al., 2006; Dejnirattisai et al., 2010; Rodenhuis-Zybert et al., 2010, 2011), how to present $\mathrm{E}$ protein in the context similar to that on virions without pr or prM protein in the vaccine preparation will be challenging but promising as the next generation vaccine. This might require the approach of genetic engineering or epitopemodification to better present the immunogen and induce more potent neutralizing Abs and less enhancing Abs, thus reducing the risk of ADE. An example of epitope-modified vaccine was demonstrated by the fusion loop-mutated dengue DNA vaccine, which induced comparable neutralizing Abs but less enhancing Abs in mice compared with WT DNA vaccine (Crill et al., 2012; Hughes et al., 2012). Similarly, a recent study of fusion loopmodified ZIKV mRNA vaccine showed less enhancing Abs were induced (Richner et al., 2017).

The recent discovery of novel E-dimer epitopes recognized by human cross-reactive potent neutralizing mAbs raises the possibility that the task of inducing balanced neutralizing Abs against 4 DENV serotypes by tetravalent vaccines can be achieved by using $\mathrm{E}$ dimers to induce cross-reactive anti-E dimer epitope neutralizing Abs (Dejnirattisai et al., 2015; Rouvinski et al., 2015). However, the design of recombinant $\mathrm{E}$ dimers to present the right conformation of E-dimer epitope remains to be explored.

The observations that anti-fusion loop mAbs derived from secondary DENV infection have higher binding avidity and neutralizing potency compared with those derived from primary infection (Tsai et al., 2013) suggest that during secondary infection memory B cells recognizing the common epitopes expand rapidly to generate cross-reactive, high avidity, and potent neutralizing Abs through affinity maturation. This was supported by higher level and rapid increase in serum avidity, cross-reactive memory B cells and plasmablasts after secondary DENV infection compared with primary infection (Mathew et al., 2011; Wrammert et al., 2012; Xu et al., 2012; Zompi et al., 2012, references in Tsai et al., 2013). The recent report that cross-reactive anti-E Abs contributed significantly to neutralizing activities against both exposed and non-exposed DENV serotypes after secondary DENV infection not only provides an explanation for the multitypic neutralizing Abs (Tsai et al., 2015), but also suggests a strategy of sequential heterotypic immunization with two or three serotypes of liveattenuated dengue vaccine to mimic natural DENV infection and induce immunity against all four serotypes. The epidemiological observations of higher risk of DHF/DSS during secondary infection raise concerns on the possible $\mathrm{ADE}$ and severe disease after the second dose of sequential immunization. Notably, heterotypic immunization with monovalent live-attenuated DENV vaccine in 30 individuals revealed minimal increased viremia compared with primary immunization and no severe disease (Durbin et al., 2011). In addition, the recent findings that CYD-TDV vaccine on DENV-experienced individuals showed no severe diseases and higher vaccine efficacy compared with naive individuals $(74.3-83.7$ vs. $35.5-43.2 \%)$ oppose the safety concern of sequential heterotypic immunization (Sabchareon et al., 2012; Capeding et al., 2014; Hadinegoro et al., 2015; Villar et al., 2015).

\section{CONCLUSION}

The moderate efficacy, low efficacy among dengue naïve, and increased risk of hospitalization among young children during the Phase $2 \mathrm{~b}$ and 3 trials of the first dengue vaccine (dengvaxia from Sanofi Pasteur) highlight the need for a better understanding of immunity, in particular humoral responses, after natural DENV infection. We have reviewed more than 300 human mAbs against DENV E protein and potent neutralizing epitopes reported thus far, together with human anti-prM mAbs and mouse mAbs. We have also reviewed several indepth analyses of polyclonal human sera following DENV infection. With various sophisticated technologies of generating human mAbs, it is expected that more potent neutralizing epitopes as well as non-neutralizing or enhancing epitopes will be identified. This information together with detailed analysis of different categories of neutralizing and enhancing Abs in polyclonal sera will provide not only new insights into our understanding of dengue protection and pathogenesis, but also strategies for better immunogen design to induce more potent neutralizing $\mathrm{Abs}$ and less enhancing Abs for next-generation dengue vaccine development. Building upon our increasing knowledge of human mAbs against DENV, future research should continue in-depth analysis on polyclonal sera comparing those from natural infection and immunization to fine tune the correlates or surrogates of protection of Abs, and also on the memory B-cells in combination with next-generation sequencing to better understand the Abs repertoire after DENV infection and immunization.

\section{AUTHOR CONTRIBUTIONS}

WT performed experiments, analyzed data, and wrote manuscript. HL analyzed data. f96445117@ntu.edu.tw. WW designed the study, analyzed data, and wrote manuscript.

\section{ACKNOWLEDGMENTS}

We thank Dr. Richard Kuhn and his team at the Purdue University for the permission of using cryoEM pictures in Figure 1, and Dr. Shee-Mei Lok at the Duke-NUS Graduate Medical School in Singapore for the permission of using pictures 
in Figure 3. This work was supported by grants R01AI11076901 from the National Institute of Allergy and Infectious Diseases, and P20GM103516 from the National Institute of General
Medical Sciences, NIH. The funders had no role in study design, data collection and analysis, decision to publish, or preparation of the manuscript.

\section{REFERENCES}

Aaskov, J. G., Geysen, H. M., and Mason, T. J. (1989). Serologically defined linear epitopes in the envelope protein of dengue 2 (Jamaica strain 1409). Arch. Virol. 105, 209-221.

Aguiar, M., Stollenwerk, N., and Halstead, S. B. (2016). The impact of the newly licensed dengue vaccine in endemic countries. PLoS Negl. Trop. Dis. 10:e0005179. doi: 10.1371/journal.pntd.0005179

Austin, S. K., Dowd, K. A., Shrestha, B., Nelson, C. A., Edeling, M. A., Johnson, S., et al. (2012). Structural basis of differential neutralization of DENV-1 genotypes by an antibody that recognizes a cryptic epitope. PLoS Pathog. 8:e1002930. doi: 10.1371/journal.ppat.1002930

Balsitis, S. J., Williams, K. L., Lachica, R., Flores, D., Kyle, J. L., Mehlhop, E., et al. (2010). Lethal antibody enhancement of dengue disease in mice is prevented by Fc modification. PLoS Pathog. 6:e1000790. doi: 10.1371/journal.ppat.1000790

Beltramello, M., Williams, K. L., Simmons, C. P., Macagno, A., Simonelli, L., Quyen, N. T., et al. (2010). The human immune response to dengue virus is dominated by highly cross-reactive antibodies endowed with neutralizing and enhancing activity. Cell Host Microbe 8, 271-283. doi: 10.1016/j.chom.2010.08.007

Bhatt, S., Gething, P. W., Brady, O. J., Messina, J. P., Farlow, A. W., Moyes, C. L., et al. (2013). The global distribution and burden of dengue. Nature 496, 504-507. doi: 10.1038/nature12060

Brien, J. D., Austin, S. K., Sukupolvi-Petty, S., O’Brien, K. M., Johnson, S., Fremont, D. H., et al. (2010). Genotype-specific neutralization and protection by antibodies against dengue virus type 3. J. Virol. 84, 10630-10643. doi: 10.1128/JVI.01190-10

Calisher, C. H., Karabatsos, N., Dalrymple, J. M., Shope, R. E., Porterfield, J. S., Westaway, E. G., et al. (1989). Antigenic relationships between flaviviruses as determined by cross-neutralization tests with polyclonal antisera. J. Gen. Virol. 70, 37-43. doi: 10.1099/0022-1317-70-1-37

Capeding, M. R., Tran, N. H., Hadinegoro, S. R., Ismail, H. I., Chotpitayasunondh, T., Chua, M. N., et al. (2014). Clinical efficacy and safety of a novel tetravalent dengue vaccine in healthy children in Asia: a phase 3, randomised, observer-masked, placebo-controlled trial. Lancet 384, 1358-1365. doi: 10.1016/S0140-6736(14)61060-6

Chan, A. H., Tan, H. C., Chow, A. Y., Lim, A. P., Lok, S. M., Moreland, N. J., et al. (2012). A human PrM antibody that recognizes a novel cryptic epitope on dengue E glycoprotein. PLoS ONE 7:e33451. doi: 10.1371/journal.pone.0033451

Cherrier, M. V., Kaufmann, B., Nybakken, G. E., Lok, S. M., Warren, J. T., Chen, B. R., et al. (2009). Structural basis for the preferential recognition of immature flaviviruses by a fusion-loop antibody. EMBO J. 28, 3269-3276. doi: 10.1038/emboj.2009.245

Churdboonchart, V., Bhamarapravati, N., Peampramprecha, S., and Sirinavin, S. (1991). Antibodies against dengue viral proteins in primary and secondary dengue hemorrhagic fever. Am. J. Trop. Med. Hyg. 44, 481-493. doi: 10.4269/ajtmh.1991.44.481

Cockburn, J. J., Navarro Sanchez, M. E., Fretes, N., Urvoas, A., Staropoli, I., Kikuti, C. M., et al. (2012a). Mechanism of dengue virus broad cross-neutralization by a monoclonal antibody. Structure 20, 303-314. doi: 10.1016/j.str.2012.01.001

Cockburn, J. J., Navarro Sanchez, M. E., Goncalvez, A. P., Zaitseva, E., Stura, E. A., Kikuti, C. M., et al. (2012b). Structural insights into the neutralization mechanism of a higher primate antibody against dengue virus. EMBO J. 31, 767-779. doi: 10.1038/emboj.2011.439

Costin, J. M., Zaitseva, E., Kahle, K. M., Nicholson, C. O., Rowe, D. K., Graham, A. S., et al. (2013). Mechanistic study of broadly neutralizing human monoclonal antibodies against dengue virus that target the fusion loop. J. Virol. 87, 52-66. doi: 10.1128/JVI.02273-12

Crill, W. D., and Chang, G. J. (2004). Localization and characterization of flavivirus envelope glycoprotein cross-reactive epitopes. J. Virol. 78, 13975-13986. doi: 10.1128/JVI.78.24.13975-13986.2004

Crill, W. D., Hughes, H. R., Delorey, M. J., and Chang, G. J. (2009). Humoral immune responses of dengue fever patients using epitopespecific serotype-2 virus-like particle antigens. PLoS ONE 4:e4991. doi: 10.1371/journal.pone.0004991

Crill, W. D., Hughes, H. R., Trainor, N. B., Davis, B. S., Whitney, M. T., and Chang, G. J. (2012). Sculpting humoral immunity through dengue vaccination to enhance protective immunity. Front. Immunol. 3:334. doi: 10.3389/fimmu.2012.00334

da Silva, A. N., Nascimento, E. J., Cordeiro, M. T., Gil, L. H., Abath, F. G., Montenegro, S. M., et al. (2009). Identification of continuous human B-cell epitopes in the envelope glycoprotein of dengue virus type 3 (DENV-3). PLoS ONE 4:e7425. doi: 10.1371/journal.pone.0007425

de Alwis, R., Beltramello, M., Messer, W. B., Sukupolvi-Petty, S., Wahala, W. M., Kraus, A., et al. (2011). In-depth analysis of the antibody response of individuals exposed to primary dengue virus infection. PLoS Negl. Trop. Dis. 5:e1188. doi: 10.1371/journal.pntd.0001188

de Alwis, R., Smith, S. A., Olivarez, N. P., Messer, W. B., Huynh, J. P., Wahala, W. M., et al. (2012). Identification of human neutralizing antibodies that bind to complex epitopes on dengue virions. Proc. Natl. Acad. Sci. U.S.A. 109, 7439-7444. doi: 10.1073/pnas.1200566109

de Alwis, R., Williams, K. L., Schmid, M. A., Lai, C. Y., Patel, B., Smith, S. A., et al. (2014). Dengue viruses are enhanced by distinct populations of serotype cross-reactive antibodies in human immune sera. PLoS Pathog. 10:e1004386. doi: 10.1371/journal.ppat.1004386

Dejnirattisai, W., Jumnainsong, A., Onsirisakul, N., Fitton, P., Vasanawathana, S., Limpitikul, W., et al. (2010). Cross-reacting antibodies enhance dengue virus infection in humans. Science 328, 745-748. doi: 10.1126/science.1185181

Dejnirattisai, W., Wongwiwat, W., Supasa, S., Zhang, X., Dai, X., Rouvinsky, A., et al. (2015). A new class of highly potent, broadly neutralizing antibodies isolated from viremic patients infected with dengue virus. Nat. Immunol. 16, 170-177. doi: 10.1038/ni.3058

Dowd, K. A., Jost, C. A., Durbin, A. P., Whitehead, S. S., and Pierson, T. C. (2011). A dynamic landscape for antibody binding modulates antibodymediated neutralization of West Nile virus. PLoS Pathog. 7:e1002111 doi: 10.1371/journal.ppat.1002111

Duangchinda, T., Dejnirattisai, W., Vasanawathana, S., Limpitikul, W., Tangthawornchaikul, N., Malasit, P., et al. (2010). Immunodominant Tcell responses to dengue virus NS3 are associated with DHF. Proc. Natl. Acad. Sci. U.S.A. 107,16922-16927. doi: 10.1073/pnas.1010867107

Dung, N. T., Duyen, H. T., Thuy, N. T., Ngoc, T. V., Chau, N. V., Hien, T. T. et al. (2010). Timing of CD8 $+\mathrm{T}$ cell responses in relation to commencement of capillary leakage in children with dengue. J. Immunol. 184, 7281-7287. doi: 10.4049/jimmunol.0903262

Durbin, A. P., Schmidt, A., Elwood, D., Wanionek, K. A., Lovchik, J., Thumar, B., et al. (2011). Heterotypic dengue infection with live attenuated monotypic dengue virus vaccines: implications for vaccination of populations in areas where dengue is endemic. J. Infect. Dis. 203, 327-334. doi: 10.1093/infdis/jiq059

Edeling, M. A., Austin, S. K., Shrestha, B., Dowd, K. A., Mukherjee, S., Nelson, C. A., et al. (2014). Potent dengue virus neutralization by a therapeutic antibody with low monovalent affinity requires bivalent engagement. PLoS Pathog. 10:e1004072. doi: 10.1371/journal.ppat.1004072

Fibriansah, G., Ibarra, K. D., Ng, T. S., Smith, S. A., Tan, J. L., Lim, X. N., et al. (2015a). Cryo-EM structure of an antibody that neutralizes dengue virus type 2 by locking E protein dimers. Science 349, 88-91. doi: 10.1126/science.aa a 8651

Fibriansah, G., Tan, J. L., Smith, S. A., de Alwis, A. R., Ng, T. S., Kostyuchenko, V. A., et al. (2014). A potent anti-dengue human antibody preferentially recognizes the conformation of $\mathrm{E}$ protein monomers assembled on the virus surface. EMBO Mol. Med. 6, 358-371. doi: 10.1002/emmm.201303404

Fibriansah, G., Tan, J. L., Smith, S. A., de Alwis, R., Ng, T. S., Kostyuchenko, V. A., et al. (2015b). A highly potent human antibody neutralizes dengue virus 
serotype 3 by binding across three surface proteins. Nat. Commun. 6:6341. doi: $10.1038 /$ ncomms7341

Flasche, S., Jit, M., Rodríguez-Barraquer, I., Coudeville, L., Recker, M., Koelle, K., et al. (2016). The long-term safety, public health impact, and costeffectiveness of routine vaccination with a recombinant, live-attenuated dengue vaccine (dengvaxia): a model comparison study. PLoS Med. 13:e1002181. doi: 10.1371/journal.pmed.1002181

Flipse, J., and Smit, J. M. (2015). The complexity of a dengue vaccine: a review of the human antibody response. PLoS Negl. Trop. Dis. 9:e0003749. doi: 10.1371/journal.pntd.0003749

Gallichotte, E. N., Widman, D. G., Yount, B. L., Wahala, W. M., Durbin, A., Whitehead, S., et al. (2015). A new quaternary structure epitope on dengue virus serotype 2 is the target of durable type-specific neutralizing antibodies. MBio 6, e01461-e01415. doi: 10.1128/mBio.01461-15

Gibbons, R. V., Kalanarooj, S., Jarman, R. G., Nisalak, A., Vaughn, D. W., Endy, T. P., et al. (2007). Analysis of repeat hospital admissions for dengue to estimate the frequency of third or fourth dengue infections resulting in admissions and dengue hemorrhagic fever, and serotype sequences. Am. J. Trop. Med. Hyg. 77, 910-913.

Goncalvez, A. P., Engle, R. E., St Claire, M., Purcell, R. H., and Lai, C. J. (2007). Monoclonal antibody-mediated enhancement of dengue virus infection in vitro and in vivo and strategies for prevention. Proc. Natl. Acad. Sci. U.S.A. 104, 9422-9427. doi: 10.1073/pnas.0703498104

Gromowski, G. D., and Barrett, A. D. (2007). Characterization of an antigenic site that contains a dominant, type-specific neutralization determinant on the envelope protein domain III (ED3) of dengue 2 virus. Virology 366, 349-360. doi: 10.1016/j.virol.2007.05.042

Gromowski, G. D., Barrett, N. D., and Barrett, A. D. (2008). Characterization of dengue virus complex-specific neutralizing epitopes on envelope protein domain III of dengue 2 virus. J. Virol. 82, 8828-8837. doi: 10.1128/JVI.00606-08

Guy, B., Briand, O., Lang, J., Saville, M., and Jackson, N. (2015). Development of the Sanofi Pasteur tetravalent dengue vaccine: One more step forward. Vaccine 33, 7100-7111. doi: 10.1016/j.vaccine.2015.09.108

Guzman, M. G., and Harris, E. (2015). Dengue. Lancet 385, 453-465. doi: 10.1016/S0140-6736(14)60572-9

Hadinegoro, S. R., Arredondo-García, J. L., Capeding, M. R., Deseda, C., Chotpitayasunondh, T., Dietze, R., et al. (2015). Efficacy and long-term safety of a dengue vaccine in regions of endemic disease. N. Engl. J. Med. 373, 1195-1206. doi: 10.1056/NEJMoa1506223

Hadjilaou, A., Green, A. M., Coloma, J., and Harris, E. (2015). Single-cell analysis of B cell/antibody cross-reactivity using a novel multicolor fluorospot assay. J. Immunol. 195, 3490-3496. doi: 10.4049/jimmunol.1500918

Halstead, S. B. (1988). Pathogenesis of dengue: challenges to molecular biology. Science 239, 476-481. doi: 10.1126/science.3277268

Halstead, S. B. (2003). Neutralization and antibody-dependent enhancement of dengue viruses. Adv. Virus Res. 60, 421-467. doi: 10.1016/S0065-3527(03)60011-4

Halstead, S. B. (2016). Critique of World Health Organization recommendation of a dengue vaccine. J. Infect. Dis. 214, 1793-1795. doi: 10.1093/infdis/jiw340

Halstead, S. B., and O'Rourke, E. J. (1977). Antibody-enhanced dengue virus infection in primate leukocytes. Nature 265, 739-741. doi: 10.1038/265739a0

Halstead, S. B., and Russell, P. K. (2016). Protective and immunological behavior of chimeric yellow fever dengue vaccine. Vaccine 34, 1643-1647. doi: 10.1016/j.vaccine.2016.02.004

Harenberg, A., Begue, S., Mamessier, A., Gimenez-Fourage, S., Ching Seah, C., Wei Liang, A., et al. (2013). Persistence of Th1/Tc1 responses one year after tetravalent dengue vaccination in adults and adolescents in Singapore. Hum. Vaccin. Immunother. 9, 2317-2325. doi: 10.4161/hv.25562

Huang, K. J., Yang, Y. C., Lin, Y. S., Huang, J. H., Liu, H. S., Yeh, T. M., et al. (2006). The dual-specific binding of dengue virus and target cells for the antibody-dependent enhancement of dengue virus infection. J. Immunol. 176, 2825-2832. doi: 10.4049/jimmunol.176.5.2825

Hughes, H. R., Crill, W. D., and Chang, G. J. (2012). Manipulation of immunodominant dengue virus E protein epitopes reduces potential antibodydependent enhancement. Virol. J. 9:115. doi: 10.1186/1743-422X-9-115

Imrie, A., Meeks, J., Gurary, A., Sukhbaatar, M., Truong, T. T., Cropp, C. B., et al. (2007). Antibody to dengue 1 detected more than 60 years after infection. Viral Immunol. 20, 672-675. doi: 10.1089/vim.2007.0050
Innis, B. L. (1997). “Antibody responses to dengue virus infection," in Dengue and Dengue Hemorrhagic Fever, eds D. J. Gubler and G. Kuno (Cambridge, MA: CAB International), 221-244.

Ishikawa, T., Yamanaka, A., and Konishi, E. (2014). A review of successful flavivirus vaccines and the problems with those flaviviruses for which vaccines are not yet available. Vaccine 32, 1326-1337. doi: 10.1016/j.vaccine.2014.01.040

Jarmer, J., Zlatkovic, J., Tsouchnikas, G., Vratskikh, O., Strau,ß, J., Aberle, J. H., et al. (2014). Variation of the specificity of the human antibody responses after tick-borne encephalitis virus infection and vaccination. J. Virol. 88, 13845-13857. doi: 10.1128/JVI.02086-14

Junjhon, J., Edwards, T. J., Utaipat, U., Bowman, V. D., Holdaway, H. A., Zhang, W., et al. (2010). Influence of pr-M cleavage on the heterogeneity of extracellular dengue virus particles. J. Virol. 84, 8353-8358. doi: 10.1128/JVI.00696-10

Kielian, M., and Rey, F. A. (2006). Virus membrane-fusion proteins: more than one way to make a hairpin. Nat. Rev. Microbiol. 4, 67-76. doi: 10.1038/nrmicro1326

Kuhn, R. J., Zhang, W., Rossmann, M. G., Pletnev, S. V., Corver, J., Lenches, E., et al. (2002). Structure of dengue virus: implications for flavivirus organization, maturation, and fusion. Cell 108, 717-725. doi: 10.1016/S0092-8674(02)00660-8

Lai, C. Y., Tsai, W. Y., Lin, S. R., Kao, C. L., Hu, S. P., King, C. C., et al. (2008). Antibodies to envelope glycoprotein of dengue virus during the natural course of infection are predominantly cross-reactive and recognize epitopes containing highly conserved residues at the fusion loop of domain II. J. Virol. 82, 6631-6643. doi: 10.1128/JVI.00316-08

Lai, C. Y., Williams, K. L., Wu, Y. C., Knight, S., Balmaseda, A., Harris, E., et al. (2013). Analysis of cross-reactive antibodies recognizing the fusion loop of envelope protein and correlation with neutralizing antibody titers in Nicaraguan dengue cases. PLoS Negl. Trop. Dis. 7:e2451 doi: 10.1371/journal.pntd.0002451

Li, L., Lok, S. M., Yu, I. M., Zhang, Y., Kuhn, R. J., Chen, J., et al. (2008). The flavivirus precursor membrane-envelope protein complex: structure and maturation. Science 319, 1830-1834. doi: 10.1126/science.1153263

Lin, H. E., Tsai, W. Y., Liu, I. J., Li, P. C., Liao, M. Y., Tsai, J. J., et al. (2012). Analysis of epitopes on dengue virus envelope protein recognized by monoclonal antibodies and polyclonal human sera by a high-throughput assay. PLoS Negl. Trop. Dis. 6:e1447. doi: 10.1371/journal.pntd.0001447

Lok, S. M., Kostyuchenko, V., Nybakken, G. E., Holdaway, H. A., Battisti, A. J., Sukupolvi-Petty, S., et al. (2008). Binding of a neutralizing antibody to dengue virus alters the arrangement of surface glycoproteins. Nat. Struct. Mol. Biol. 15, 312-317. doi: 10.1038/nsmb.1382

Manoff, S. B., George, S. L., Bett, A. J., Yelmene, M. L., Dhanasekaran, G., Eggemeyer, L., et al. (2015). Preclinical and clinical development of a dengue recombinant subunit vaccine. Vaccine 33, 7126-7134. doi: 10.1016/j.vaccine.2015.09.101

Mathew, A., Kurane, I., Rothman, A. L., Zeng, L. L., Brinton, M. A., and Ennis, F. A. (1996). Dominant recognition by human CD8+ cytotoxic T lymphocytes of dengue virus nonstructural proteins NS3 and NS1.2a. J. Clin. Invest. 98, 1684-1691.

Mathew, A., West, K., Kalayanarooj, S., Gibbons, R. V., Srikiatkhachorn, A., Green, S., et al. (2011). B-cell responses during primary and secondary dengue virus infections in humans. J. Infect. Dis. 204, 1514-1522. doi: 10.1093/infdis/jir607

Megret, F., Hugnot, J. P., Falconar, A., Gentry, M. K., Morens, D. M., Murray, J. M., et al. (1992). Use of recombinant fusion proteins and monoclonal antibodies to define linear and discontinuous antigenic sites on the dengue virus envelope glycoprotein. Virology 187, 480-491.

Messer, W. B., de Alwis, R., Yount, B. L., Royal, S. R., Huynh, J. P., Smith, S. A., et al. (2014). Dengue virus envelope protein domain I/II hinge determines long-lived serotype-specific dengue immunity. Proc. Natl. Acad. Sci. U.S.A. 111, 1939-1944. doi: 10.1073/pnas.1317350111

Messer, W. B., de Alwis, R., Yount, B. L., Royal, S. R., Huynh, J. P., Smith, S. A., et al. (2015). Dengue virus envelope protein domain I/II hinge determines long-lived serotype-specific dengue immunity. Proc. Natl. Acad. Sci. U.S.A. 112, E2738. doi: 10.1073 /pnas. 1506982112

Midgley, C. M., Flanagan, A., Tran, H. B., Dejnirattisai, W., Chawansuntati, K., Jumnainsong, A., et al. (2012). Structural analysis of a dengue cross-reactive antibody complexed with envelope domain III reveals the molecular basis of cross-reactivity. J. Immunol. 188, 4971-4979. doi: 10.4049/jimmunol.1200227 
Modis, Y., Ogata, S., Clements, D., and Harrison, S. C. (2004). Structure of the dengue virus envelope protein after membrane fusion. Nature 427, 313-319. doi: 10.1038 /nature02165

Mongkolsapaya, J., Dejnirattisai, W., Xu, X. N., Vasanawathana, S., Tangthawornchaikul, N., Chairunsri, A., et al. (2003). Original antigenic sin and apoptosis in the pathogenesis of dengue hemorrhagic fever. Nat. Med. 9, 921-927. doi: 10.1038/nm887

Mukhopadhyay, S., Kuhn, R. J., and Rossmann, M. G. (2005). A structural perspective of the flavivirus life cycle. Nat. Rev. Microbiol. 3, 13-22. doi: $10.1038 /$ nrmicro 1067

Murphy, B. R., and Whitehead, S. S. (2011). Immune response to dengue virus and prospects for a vaccine. Annu. Rev. Immunol. 29, 587-619. doi: 10.1146/annurev-immunol-031210-101315

Nelson, S., Jost, C. A., Xu, Q., Ess, J., Martin, J. E., Oliphant, T., et al. (2008). Maturation of West Nile virus modulates sensitivity to antibodymediated neutralization. PLoS Pathog. 4:e1000060. doi: 10.1371/journal.ppat.10 00060

Nivarthi, U. K., Kose, N., Sapparapu, G., Widman, D., Gallichotte, E., Pfaff, J. M., et al. (2017). Mapping the human memory B cell and serum neutralizing antibody responses to dengue virus serotype 4 infection and vaccination. J Virol. 91:e02041-16. doi: 10.1128/JVI.02041-16

Olkowski, S., Forshey, B. M., Morrison, A. C., Rocha, C., Vilcarromero, S., Halsey, E. S., et al. (2013). Reduced risk of disease during postsecondary dengue virus infections. J. Infect. Dis. 208, 1026-1033. doi: 10.1093/infdis/jit273

Perera, R., and Kuhn, R. J. (2008). Structural proteomics of dengue virus. Curr. Opin. Microbiol. 11, 369-377. doi: 10.1016/j.mib.2008.06.004

Perera, R., Khaliq, M., and Kuhn, R. J. (2008). Closing the door on flaviviruses: entry as a target for antiviral drug design. Antiviral Res. 80, 11-22. doi: 10.1016/j.antiviral.2008.05.004

Pierson, T. C., and Diamond, M. S. (2013). "Flaviviruses," in Fields Virology, 6th $E d n$, eds D. M. Knipe and P. M. Howley (Philadelphia, PA: Lippincott William \& Wilkins), 747-794.

Pierson, T. C., Fremont, D. H., Kuhn, R. J., and Diamond, M. S. (2008). Structural insights into the mechanisms of antibody-mediated neutralization of flavivirus infection: implications for vaccine development. Cell Host Microbe 4, 229-238. doi: 10.1016/j.chom.2008.08.004

Pierson, T. C., Xu, Q., Nelson, S., Oliphant, T., Nybakken, G. E., Fremont, D. H., et al. (2007). The stoichiometry of antibody-mediated neutralization and enhancement of West Nile virus infection. Cell Host Microbe 1, 135-145. doi: 10.1016/j.chom.2007.03.002

Priyamvada, L., Cho, A., Onlamoon, N., Zheng, N. Y., Huang, M., Kovalenkov, Y., et al. (2016). B cell responses during secondary dengue virus infection are dominated by highly cross-reactive, memory-derived plasmablasts. J. Virol. 90, 5574-5585. doi: 10.1128/JVI.03203-15

Richner, J. M., Himansu, S., Dowd, K. A., Butler, S. L., Salazar, V., Fox, J. M., et al. (2017). Modified mRNA vaccines protect against zika virus infection. Cell 168, 1114.e10-1125.e10. doi: 10.1016/j.cell.2017.02.017

Rodenhuis-Zybert, I. A., Moesker, B., da Silva Voorham, J. M., van der EndeMetselaar, H., Diamond, M. S., Wilschut, J., et al. (2011). A fusion-loop antibody enhances the infectious properties of immature flavivirus particles. J. Virol. 85, 11800-11808. doi: 10.1128/JVI.05237-11

Rodenhuis-Zybert, I. A., van der Schaar, H. M., da Silva Voorham, J. M., van der Ende-Metselaar, H., Lei, H. Y., Wilschut, J., et al. (2010). Immature dengue virus: a veiled pathogen? PLoS Pathog. 6:e1000718. doi: 10.1371/journal.ppat.1000718

Roehrig, J. T., Bolin, R. A., and Kelly, R. G. (1998). Monoclonal antibody mapping of the envelope glycoprotein of the dengue 2 virus, Jamaica. Virology 246, 317-328.

Roehrig, J. T., Volpe, K. E., Squires, J., Hunt, A. R., Davis, B. S., and Chang, G. J. J. (2004). Contribution of disulfide bridging to epitope expression of the dengue type 2 virus envelope glycoprotein. J. Virol. 78, 2648-2652. doi: 10.1128/JVI.78.5.2648-2652.2004

Rothman, A. L. (2011). Immunity to dengue virus: a tale of original antigenic sin and tropical cytokine storms. Nat. Rev. Immunol. 11, 532-543. doi: $10.1038 /$ nri3014

Rothman, A. L., Currier, J. R., Friberg, H. L., and Mathew, A. (2015). Analysis of cell-mediated immune responses in support of dengue vaccine development efforts. Vaccine 33, 7083-7090. doi: 10.1016/j.vaccine.2015.09.104
Rouvinski, A., Guardado-Calvo, P., Barba-Spaeth, G., Duquerroy, S., Vaney, M. C., Kikuti, C. M., et al. (2015). Recognition determinants of broadly neutralizing human antibodies against dengue viruses. Nature 520, 109-113. doi: $10.1038 /$ nature 14130

Sabchareon, A., Wallace, D., Sirivichayakul, C., Limkittikul, K., Chanthavanich, P., Suvannadabba, S., et al. (2012). Protective efficacy of the recombinant, live-attenuated, CYD tetravalent dengue vaccine in Thai schoolchildren: a randomised, controlled phase $2 \mathrm{~b}$ trial. Lancet 380, 1559-1567. doi: 10.1016/S0140-6736(12)61428-7

Sabin, A. B. (1952). Research on dengue during World War II. Am. J. Trop. Med. Hyg. 1, 30-50.

Schwartz, L. M., Halloran, M. E., Durbin, A. P., and Longini, I. M. Jr. (2015). The dengue vaccine pipeline: Implications for the future of dengue control. Vaccine 33, 3293-3298. doi: 10.1016/j.vaccine.2015.05.010

Screaton, G., Mongkolsapaya, J., Yacoub, S., and Roberts, C. (2015). New insights into the immunopathology and control of dengue virus infection. Nat. Rev. Immunol. 12, 745-759. doi: 10.1038/nri3916

Se-Thoe, S. Y., Ng, M. M., and Ling, A. E. (1999). Retrospective study of Western blot profiles in immune sera of natural dengue virus infections. J. Med. Virol. 57, 322-330.

Shresta, S., Sharar, K. L., Prigozhin, D. M., Beatty, P. R., and Harris, E. (2006). Murine model for dengue virus-induced lethal disease with increased vascular permeability. J. Virol. 80, 10208-10217. doi: 10.1128/JVI.00062-06

Shrestha, B., Brien, J. D., Sukupolvi-Petty, S., Austin, K., Edeling, M. A., Kim, T., et al. (2010). The development of therapeutic antibodies that neutralize homologous and heterologous genotypes of dengue virus type 1. PLoS Pathog. 6:e1000823. doi: 10.1371/journal.ppat.1000823

Smith, S. A., de Alwis, A. R., Kose, N., Harris, E., Ibarra, K. D., Kahle, K. M., et al. (2013a). The potent and broadly neutralizing human dengue virusspecific monoclonal antibody 1C19 reveals a unique cross-reactive epitope on the bc loop of domain II of the envelope protein. MBio 4, e00873-e00813. doi: $10.1128 / \mathrm{mBio} .00873-13$

Smith, S. A., de Alwis, A. R., Kose, N., Jadi, R. S., de Silva, A. M., and Crowe, J. E. Jr. (2014). Isolation of dengue virus-specific memory B cells with live virus antigen from human subjects following natural infection reveals the presence of diverse novel functional groups of antibody clones. J. Virol. 88, 12233-12241. doi: 10.1128/JVI.00247-14

Smith, S. A., de Alwis, R., Kose, N., Durbin, A. P., Whitehead, S. S., de Silva, A. M., et al. (2013b). Human monoclonal antibodies derived from memory B cells following live attenuated dengue virus vaccination or natural infection exhibit similar characteristics. J. Infect. Dis. 207, 1898-1908. doi: 10.1093/infdis/jit119

Smith, S. A., Nivarthi, U. K., de Alwis, R., Kose, N., Sapparapu, G., Bombardi, R., et al. (2015). Dengue virus prM-specific human monoclonal antibodies with virus replication enhancing properties recognize a single immunodominant antigenic site. J. Virol. 90, 780-789. doi: 10.1128/JVI.01805-15

Smith, S. A., Zhou, Y., Olivarez, N. P., Broadwater, A. H., de Silva, A. M., and Crowe, J. E. Jr. (2012). Persistence of circulating memory B cell clones with potential for dengue virus disease enhancement for decades following infection. J. Virol. 86, 2665-2675. doi: 10.1128/JVI.06335-11

Stiasny, K., Kiermayr, S., Holzmann, H., and Heinz, F. X. (2006). Cryptic properties of a cluster of dominant flavivirus cross-reactive antigenic sites. J. Virol. 80, 9557-9568, doi: 10.1128/JVI.00080-06

Sukupolvi-Petty, S., Austin, K., Purtha, W. E., Oliphant, T., Nybakken, G. E., Schlesinger, J. J., et al. (2007). Type and subcomplex-specific neutralizing antibodies against domain III of dengue virus type 2 envelope protein recognize adjacent epitopes. J. Virol. 81, 12816-12826. doi: 10.1128/JVI.00432-07

Sukupolvi-Petty, S., Austin, S. K., Engle, M., Brien, J. D., Dowd, K. A., Williams, K. L., et al. (2010). Structure and function analysis of therapeutic monoclonal antibodies against dengue virus type 2. J. Virol. 84, 9227-9239. doi: 10.1128/JVI.01087-10

Sukupolvi-Petty, S., Brien, J. D., Austin, S. K., Shrestha, B., Swayne, S., Kahle, K., et al. (2013). Functional analysis of antibodies against dengue virus type 4 reveals strain-dependent epitope exposure that impacts neutralization and protection. J. Virol. 87, 8826-8842. doi: 10.1128/JVI.01314-13

Teoh, E. P., Kukkaro, P. P., Teo, E. W., Lim, A. P., Tan, T. T., Yip, A., et al. (2012). The structural basis for serotype-specific neutralization of dengue virus by a human antibody. Sci. Transl. Med. 4, 139 ra83. doi: $10.1126 /$ scitranslmed.3003888 
Thomas, S. J. (2015). Preventing dengue - is the possibility now a reality? N. Engl. J. Med. 372, 172-173. doi: 10.1056/NEJMe1413146

Thompson, B. S., Moesker, B., Smit, J. M., Wilschut, J., Diamond, M. S., and Fremont, D. H. (2009). A therapeutic antibody against west nile virus neutralizes infection by blocking fusion within endosomes. PLoS Pathog. 5:e1000453. doi: 10.1371/journal.ppat.1000453

Tsai, W. Y., Durbin, A., Tsai, J. J., Whitehead, S., and Wang, W. K. (2015). Complexity of neutralization antibodies against multiple dengue viral serotypes after heterotypic immunization and secondary infection revealed by in-depth analysis of cross-reactive antibodies. J. Virol. 89, 7348-7362. doi: 10.1128/JVI.00273-15

Tsai, W. Y., Lai, C. Y., Wu, Y. C., Lin, H. E., Edwards, E., Jumnainsong, A., et al. (2013). High avidity and potent neutralizing cross-reactive human monoclonal antibodies derived from secondary dengue virus infection. J. Virol. 87, 12562-12575. doi: 10.1128/JVI.00871-13

Valdes, K., Alvarez, M., Pupo, M., Vazquez, S., Rodriguez, R., and Guzman, M. G. (2000). Human Dengue antibodies against structural and nonstructural proteins. Clin. Diagn. Lab. Immunol. 7, 856-857. doi: $10.1128 /$ cdli.7.5.856-857.2000

VanBlargan, L. A., Mukherjee, S., Dowd, K. A., Durbin, A. P., Whitehead, S. S., and Pierson, T. C. (2013). The type-specific neutralizing antibody response elicited by a dengue vaccine candidate is focused on two amino acids of the envelope protein. PLoS Pathog. 9:e1003761. doi: 10.1371/journal.ppat.1003761

Vaughn, D. W., Nisalak, A., Solomon, T., Kalayanarooj, S., Dung, N. M., Kneen, R., et al. (1999). Rapid serologic diagnosis of dengue virus infection using a commercial capture ELISA that distinguishes primary and secondary infections. Am. J. Trop. Med. Hyg. 60, 693-698.

Villar, L., Dayan, G. H., Arredondo-García, J. L., Rivera, D. M., Cunha, R., Deseda, C., et al. (2015). Efficacy of a Tetravalent Dengue Vaccine in Children in Latin America. N. Engl. J. Med. 372, 113-123. doi: 10.1056/NEJMoa1411037

Vratskikh, O., Stiasny, K., Zlatkovic, J., Tsouchnikas, G., Jarmer, J., Karrer, U., et al. (2013). Dissection of antibody specificities induced by yellow fever vaccination. PLoS Pathog. 9:e1003458. doi: 10.1371/journal.ppat.1003458

Wahala, W. M., Kraus, A. A., Haymore, L. B., Accavitti-Loper, M. A., and de Silva, A. M. (2009). Dengue virus neutralization by human immune sera: role of envelope protein domain III-reactive antibody. Virology 392, 103-113. doi: 10.1016/j.virol.2009.06.037

Weiskopf, D., and Sette, A. (2014). T-cell immunity to infection with dengue virus in humans. Front. Immunol. 5:93. doi: 10.3389/fimmu.2014.00093

Weiskopf, D., Angelo, M. A., Bangs, D. J., Sidney, J., Paul, S., Peters, B., et al. (2015). The human CD8+ $\mathrm{T}$ cell responses induced by a live attenuated tetravalent dengue vaccine are directed against highly conserved epitopes. J. Virol. 89. 120-128. doi: 10.1128/jvi.02129-14

Weiskopf, D., Angelo, M. A., de Azeredo, E. L., Sidney, J., Greenbaum, J. A., Fernando, A. N., et al. (2013). Comprehensive analysis of dengue virus-specific responses supports an HLA-linked protective role for CD8+ T cells. Proc. Natl. Acad. Sci. U.S.A. 110, E2046-E2053. doi: 10.1073/pnas.1305227110

Whitehead, S. S. (2016). Development of TV003/TV005, a single dose, highly immunogenic live attenuated dengue vaccine; what makes this vaccine different from the Sanofi-Pasteur $\mathrm{CYD}^{\mathrm{TM}}$ vaccine? Expert Rev. Vaccines 15, 509-517. doi: $10.1586 / 14760584.2016 .1115727$
Wilder-Smith, A., Vannice, K. S., Hombach, J., Farrar, J., and Nolan, T. (2016). Population Perspectives and World Health Organization Recommendations for CYD-TDV Dengue Vaccine. J. Infect. Dis. 214, 1796-1799. doi: 10.1093/infdis/jiw341

Wilson, P. C., and Andrews, S. F. (2012). Tools to therapeutically harness the human antibody response. Nat. Rev. Immunol. 12, 709-719. doi: $10.1038 /$ nri3285

World Health Organization (2009). Dengue Hemorrhagic Fever: Diagnosis, Treatment, Prevention and Control, $3 r d$ Edn, Geneva.

Wrammert, J., Onlamoon, N., Akondy, R. S., Perng, G. C., Polsrila, K., Chandele, A., et al. (2012). Rapid and massive virus-specific plasmablast responses during acute dengue virus infection in humans. J. Virol. 86, 2911-2918. doi: 10.1128/JVI.06075-11

Xu, M., Hadinoto, V., Appanna, R., Joensson, K., Toh, Y. X., Balakrishnan, T., et al. (2012). Plasmablasts generated during repeated dengue infection are virus glycoprotein-specific and bind to multiple virus serotypes. J. Immunol. 189, 5877-5885. doi: 10.4049/jimmunol.1201688

Yu, I. M., Zhang, W., Holdaway, H. A., Li, L., Kostyuchenko, V. A., Chipman, P. R., et al. (2008). Structure of the immature dengue virus at low $\mathrm{pH}$ primes proteolytic maturation. Science 319, 1834-1837. doi: 10.1126/science.1153264

Zellweger, R. M., Prestwood, T. R., and Shresta, S. (2010). Enhanced infection of liver sinusoidal endothelial cells in a mouse model of antibody-induced severe dengue disease. Cell Host Microbe 7, 128-139. doi: 10.1016/j.chom.2010. 01.004

Zhang, W., Chipman, P. R., Corver, J., Johnson, P. R., Zhang, Y., Mukhopadhyay, S., et al. (2003). Visualization of membrane protein domains by cryo-electron microscopy of dengue virus. Nat. Struct. Biol. 10, 907-912. doi: 10.1038/nsb990

Zhang, X., Ge, P., Yu, X., Brannan, J. M., Bi, G., Zhang, Q., et al. (2013). Cryo-EM structure of the mature dengue virus at 3.5-Å resolution. Nat. Struct. Mol. Biol. 20, 105-110. doi: $10.1038 / \mathrm{nsmb} .2463$

Zhang, Y., Corver, J., Chipman, P. R., Zhang, W., Pletnev, S. V., Sedlak, D., et al. (2003). Structures of immature flavivirus particles. EMBO J. 22, 2604-2613. doi: 10.1093/emboj/cdg270

Zlatkovic, J., Stiasny, K., and Heinz, F. X. (2011). Immunodominance and functional activities of antibody responses to inactivated West Nile virus and recombinant subunit vaccines in mice. J. Virol. 85, 1994-2003. doi: 10.1128/JVI.01886-10

Zompi, S., Montoya, M., Pohl, O., Balmaseda, A., and Harris, E. (2012). Dominant cross-reactive $\mathrm{B}$ cell response during secondary acute dengue virus infection in humans. PLoS Negl. Trop. Dis. 6:e1568. doi: 10.1371/journal.pntd.0001568

Conflict of Interest Statement: The authors declare that the research was conducted in the absence of any commercial or financial relationships that could be construed as a potential conflict of interest.

Copyright (@) 2017 Tsai, Lin and Wang. This is an open-access article distributed under the terms of the Creative Commons Attribution License (CC BY). The use, distribution or reproduction in other forums is permitted, provided the original author(s) or licensor are credited and that the original publication in this journal is cited, in accordance with accepted academic practice. No use, distribution or reproduction is permitted which does not comply with these terms. 